\title{
Processos geomorfológicos e danos derivados da corrida de detritos de janeiro 2011 na bacia do Córrego do Príncipe, Teresópolis - Região Serrana do Rio de Janeiro.
}

\author{
Geomorphological processes and associated damage of a debris flow in January \\ 2011 in Córrego do Príncipe watershed, Teresópolis - Mountainous Region of Rio de \\ Janeiro State.
}

\author{
Muriel Conq ${ }^{* 1}$, Carla Semiramis Silveira ${ }^{2}$ e Francisco Dourado ${ }^{3}$ \\ ${ }^{1}$ Universidade de Montpellier III, Montpellier, França \\ ${ }^{2}$ Universidade Federal Fluminense, Instituto de Química,Departamento de Geoquímica,Brasil \\ ${ }^{3}$ Departamento de Geologia Aplicada, Instituto de Geologia Universidade do Estado do Rio de Janeiro, Brasil
}

\begin{abstract}
Resumo
O Córrego do Príncipe (1.197 ha), Região Serrana do estado do Rio de Janeiro foi gravemente atingido durante a corrida de detritos do dia 12 de janeiro de 2011. O evento foi originado por uma precipitação extrema que resultou em uma catástrofe de destruição e mortes. Observações de campo em conjunto com análise de imagens de satélite Quickbird (resolução 0,6 m, agosto/2006 e fotos aéreas 1:8.000, maio/2011) identificaram e classificaram os danos nas moradias associando com processos geomorfológicos de erosão e deposição. A corrida de detritos se estendeu por aproximadamente $4,8 \mathrm{Km}$, sendo os dois primeiros caracterizados por processos de erosão e transporte de blocos, matacões e material fino. Os últimos 2,8 km foram de deposição deste material. Os danos nas construções foram de maior intensidade na zona de erosão/transporte e quatro pontos de estrangulamento tiveram importância na ampliação dos danos próximos a eles. Os blocos e matacões foram originados principalmente pela exumação de depósitos antigos do leito do rio. Na zona de deposição a sedimentação de material fino superou os $2 \mathrm{~m}$ de espessura soterrando parte das moradias e vias. Em média $42 \%$ das construções sofreram danos elevados (difícil reconstrução) no vale do Córrego do Príncipe.
\end{abstract}

Palavras-chave: Corrida de detritos. Danos. Bacia de drenagem. Catástrofe.

\begin{abstract}
The Córrego do Principe (1,197 ha) watershed located at the mountainous range "Região Serrana" of the state of Rio de Janeiro was seriously affected by a debris flow that took place on January 12th, 2011. The event was triggered by an extreme rainfall that resulted in a major disaster causing destruction and deaths. Field observations together with Quickbird satellite images analysis (0.6 m resolution August/2006 and 1:8,000 aerial pictures May/2011) identified and classified the damages affecting buildings associated with geomorphological processes of erosion and deposition. The debris flow extended for about $4.8 \mathrm{~km}$, the first two being characterized by erosion and transport of blocks, boulders and fine material. The deposition of this material happened on the last 2.8 kilometers. Buildings damages of greater intensity were observed associated with the erosion / transport area and four knickpoints have proven to significantly amplify the damages in their surroundings. Blocks and boulders came primarily from exhumation of riverbed ancient deposits. The deposition zone showed more than $2 \mathrm{~m}$ thickness sedimentation that buried part of the buildings and roads. High damage (difficult to reconstruct) covered an average of $42 \%$ of the buildings in the Córrego do Principe watershed.
\end{abstract}

Keywords: Debris flow. Damage. Watershed. Disaster 


\section{Introdução}

$\mathrm{E}$

m janeiro 2011 uma chuva intensa caiu na Região Serrana do Rio de Janeiro (municípios de Petrópolis, Teresópolis e Nova Friburgo) e causou o maior desastre natural registrado no Brasil, denominado de "Megadesastre". Essa chuva gerou milhares de deslizamentos sendo a maioria do tipo translacional e raso e em alguns casos gerando corridas de detritos (Avelar et al., 2011). As corridas de massa mais destruidoras e mortíferas foram as que afetaram os vales do Rio Cuiabá, em Petrópolis, do Córrego do Príncipe e do Rio Vieira, em Teresópolis e do Córrego d'Antas em Nova Friburgo (DRM, 2011).

Durante as últimas quatro décadas em função da urbanização descontrolada, aspectos topográficos e chuvas de grandes magnitudes a população do estado do Rio de Janeiro sofreu impactos de vários eventos catastróficos associados a movimentos de massa (Smyth \& Royle, 2000; Fernandes et al, 2004). Destacam-se os eventos de 1966, de 1988 e de 1996. Os movimentos de massa que causaram o desastre de 1966 forçaram a criação do Instituto de Geotécnica do Município do Rio de Janeiro (GeoRio) responsável pela elaboração de planos emergenciais e de longo prazo para a proteção das encostas. Entretanto, segundo Amaral et al. (1996), entre os anos 1966 e 1988, o número de deslizamentos de baixo volume aumentou devido à expansão da cidade do Rio de Janeiro e à falta de planejamento. Kanji et al (2003) em um levantamento histórico dos fluxos de detritos no Brasil chamam a atenção para eventos de grande destruição e morte associados a chuvas de grandes magnitudes e numerosos deslizamentos em regiões montanhosas. Segundo Lacerda (2007) os fluxos de detritos na região sudeste do Brasil são gerados por uma combinação de chuva de grande duração e intensidade e diversos des- lizamentos nos colúvios e saprolitos das encostas. Estes deslizamentos são ocasionados geralmente pela perda de coesão do material saprolítico ou coluvial.

Entre os dias 11 e 12 de janeiro de 2011, de acordo com a estação meteorológica Olaria em Nova Friburgo, em menos de 48 horas cerca de $270 \mathrm{~mm}$ de chuva precipitaram, o equivalente à previsão para todo o mês de janeiro. A intensidade da chuva atingiu $80 \mathrm{~mm} / \mathrm{h}$. Esta precipitação intensa por um período prolongado causou a saturação dos solos sendo a causa principal dos milhares de movimentos de massa na região Serrana (DRM, 2011; Avelar et al. 2011; Coelho Netto et al., 2011; Dourado et al., 2012). Alguns estudos discutiram os fatores desencadeadores destes deslizamentos e também os mecanismos de desenvolvimento das corridas de detritos (Amaral et al., 2011; Melo et al., 2011; Avelar et al, 2011; Pinto \& Freitas, 2012; Rodrigues et al., 2012; Fraifeld \& Freitas, 2013). Entre as corridas de detritos da região serrana, a do córrego do Príncipe em Teresópolis foi uma das mais destruidoras (DRM, 2011; Dourado et al. 2012). Neste contexto este trabalho tem por objetivo mapear nesta corrida as áreas de erosão/transporte e as áreas de deposição de sedimentos relacionando-as com os danos na infraestrutura local.

\section{2 Área de estudo}

O córrego do Príncipe abrange os bairros de Posse, Campo Grande e Cascata do Imbuí no município de Teresópolis, região Serrana do Estado do Rio de Janeiro, Serra dos Orgãos (setor da Serra do Mar no estado do Rio de Janeiro). O vale é accessível pelo centro de Teresópolis e também de Petrópolis pela BR-495 (Figura 1).

A bacia do Príncipe (1.197 ha) possui uma rede de drenagem que segue a orientação preferencial NW-SE,

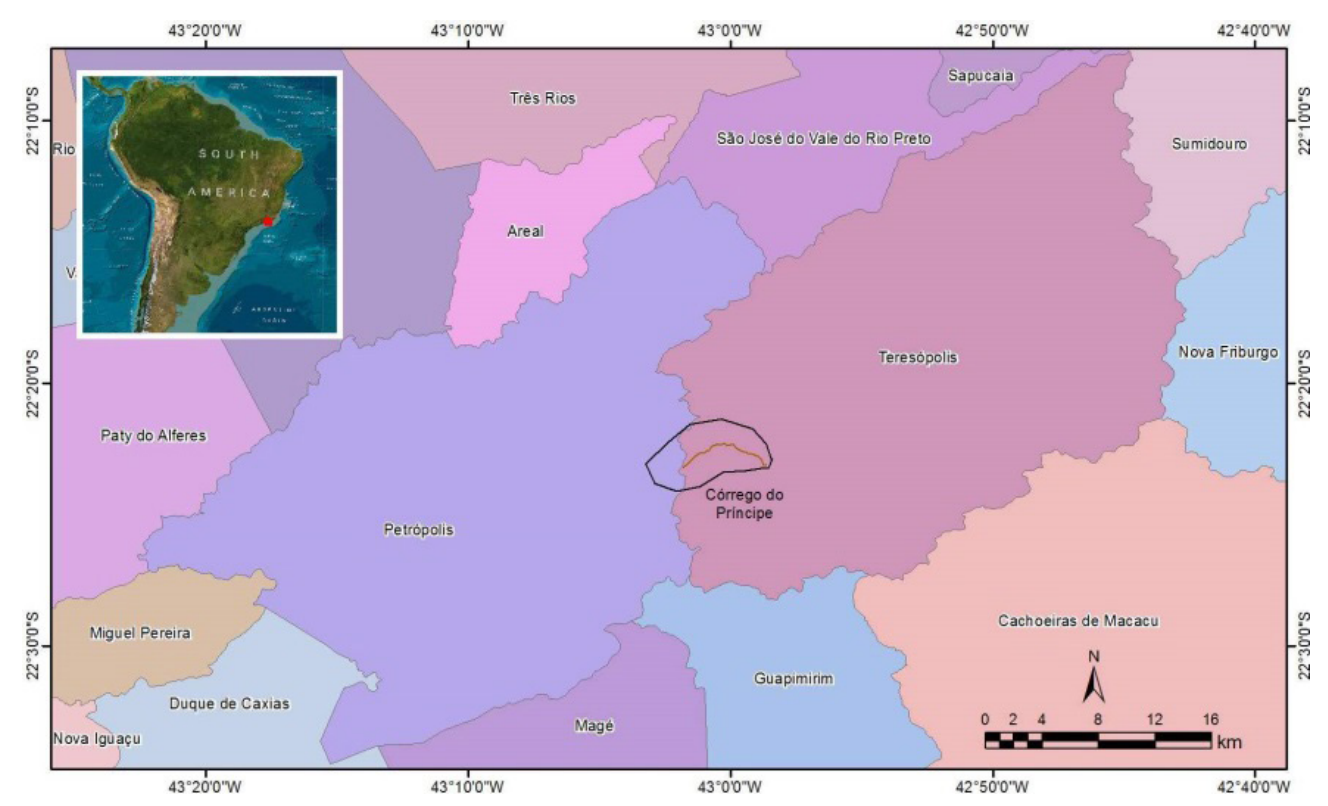

Figura 1: Localização da área de estudo no município de Teresópolis, estado do Rio de Janeiro. 
característica das redes hidrográficas da região, relacionadas à reativação das falhas no episodio de abertura do Atlântico durante o Mesozoico (Hartwig, 2006). O córrego do Príncipe é um afluente do rio Paquequer que faz parte da bacia do Piabanha, na bacia do rio Paraíba do Sul.

A Serra dos Órgãos encontra-se exposta às massas de ar oceânicas úmidas que afeiçoam o relevo escarpado característico da região. Esta escarpa exerce um papel importante como receptora das aguas pluviais do litoral e como um obstáculo aos ventos provenientes do mar causando processos erosivos intensos. A pluviosidade anual da bacia do Paquequer oscila entre $2800 \mathrm{~mm}$ na cabeceira e $1400 \mathrm{~mm}$ na sua foz. A estação chuvosa ocorre de novembro a abril quando chuvas muito fortes (maiores que $60 \mathrm{~mm} /$ dia) chegam a $10 \%$ da frequência das chuvas diárias (Silveira \& Souza, 2012). A localização da bacia do córrego do Príncipe sugere valores intermediários para a precipitação anual.

Assim o vale do Príncipe se encontra inserido no Domínio Montanhoso descrito por Gonzalez (2000) apresentando cotas superiores a $1.000 \mathrm{~m}$ e caracterizado pela presença de declives rochosos em um vale estreito e assimétrico. As cotas mais altas da bacia superam os $1.700 \mathrm{~m}$ e as mais baixas estão em torno de $800 \mathrm{~m}$. A declividade oscila entre $25^{\circ}$ e $30^{\circ}$ na face Sul (margem direita do córrego do Príncipe) enquanto a face Norte (margem esquerda) apresenta declividades superiores a $60^{\circ}$, pouca cobertura vegetal assim como muitas escarpas rochosas (Waldherr et al., 2011)

Geologicamente a bacia do córrego do Príncipe compreende 3 litologias: A unidade Rio Negro é um granada-hornblenda-gnaisse granítico de idade Paleoproterozóica; O Granito Teresópolis, de idade Proterozóico Superior, é um granito cinzento de grão fino e o Batólito Serra dos Orgãos que é um ortognaisse leucocrático, de cor cinzenta (UERJ, 1999). Os solos, do tipo Cambissolo, são pouco espessos, o que explica a alta frequência de escorregamentos translacionais de tipo "na Parroca". Os deslizamentos do tipo "na Parroca" são gerados no contato solo/rocha no topo superior das escarpas rochosas. Com a elevação da poropressão ocorre a perda de coesão do material que caí pela encosta e gera uma energia cinética dissipada no tálus depositado na base da escarpa. Assim é promovido um movimento de massa secundário com volume muito superior ao movimento primário (Dourado et al, 2012).

Os colúvios na bacia podem atingir dezena de metros de profundidade e comportam matacões e blocos em matriz argilosa.

A urbanização se deu principalmente ao longo do vale principal com moradias dispersas sobre as encostas. Administrativamente, o vale do Córrego do Príncipe compreende três bairros: Campo Grande, Posse e Cascata do Imbuí. Nos anos 1970 e 1980, a região do bairro de Campo Grande passou por um processo de favelização que atingiu o seu grau máximo no ano de 1985 com o boom demográfico que afetou todo o município. Segundo o censo de 2010 do IBGE, o bairro de Campo Grande é constituído de domicílios não legalizados ditos "aglomerados subnormais". As construções de arquitetura precária e vulnerável caracterizam a urbanização do bairro. Ao mesmo tempo, casas de veraneio de classe média e alta ocupam o bairro da Posse, o que resulta numa disparidade da urbanização no vale do Príncipe.

Segundo IBGE (2010) mais de um terço das moradias localizadas em Posse e Cascata de Imbui são ocupadas só por temporada. No total, os dois bairros mais o bairro de Campo Grande apresentam 1.354 domicílios e 2.910 moradores que serão considerados neste estudo.

\section{Metodologia}

\subsection{Fonte de dados}

A disponibilidade de imagens áreas permitiu que o mapeamento fosse feito entre as cotas $1000 \mathrm{~m}$ e $852 \mathrm{~m}$ (a foz do Córrego do Príncipe no Rio Paquequer). Para a análise foram utilizados os seguintes dados: Mapas geológicos na escala 1:50.000 (UERJ, 1999); Imagem satélite Quickbird de resolução 0,6 m de agosto de 2006; Fotos aéreas na escala 1:8.000 de maio de 2011 (Instituto Estadual do Ambiente do Rio de Janeiro - INEA); Base topográfica na escala 1:2.000 no formato Shape File (SHP/ ArcGIS) realizada pelo INEA com base nas fotos 1:8000.

Devido à ausência de cadastros públicos municipais ou estaduais disponíveis sobre a população e moradias na bacia, a pesquisa de informação se fez por meio de dados do IBGE, assim como jornais e testemunhos. Os dados do IBGE foram obtidos através do Censo 2010 e do Sistema Nacional de Pesquisa e Custos e Índices da Construção Civil (resultados de Abril 2012).

\subsection{Métodos}

O processamento dos dados foi feito através do programa ArcGIS. As observações de campo foram feitas aproximadamente um ano após o desastre (abril de 2012). Nesta mesma época os trabalhos de reabilitação e reconstrução da área estavam em um estado inicial.

Os procedimentos metodológicos feitos podem ser equiparados com a definição de inventário de movimento de massa proposta por Fell et al (2008). Segundo estes autores o inventário é um nível essencial para análise de suscetibilidade e o planejamento do uso do solo. A comparação de imagens aéreas tomadas imediatamente depois do desastre com os as observações de campo seguiram o método de analise de Leone et al. (1996). Este método foi desenvolvido para avaliar as perdas diretas e indiretas causadas por catástrofes, relacionando os fenômenos catastróficos aos danos. Ele já foi aplicado para avaliar os riscos e as perdas do Tsunami de 2004 na Indonésia (Leone et al, 2007). Metodologia similar 
Tabela 1: Classificação dos danos originados pela corrida de detritos do córrego do Príncipe (modificado de Leone et al., 1996).

Intensidade de
dano e nível de
perda (\%)

\begin{tabular}{lll}
\hline $1(1-10 \%)$ & $\begin{array}{l}\text { Danos leves não estruturais. Estabilidade não } \\
\text { afetada. }\end{array}$ & $\begin{array}{l}\text { Pintura descascada, } \\
\text { mobiliário danificado, } \\
\text { sedimentação dentro. }\end{array}$ \\
\hline $2(20-30 \%)$ & $\begin{array}{l}\text { Paredes com rachaduras. Estabilidade não } \\
\text { afetada. Reparos não urgentes. }\end{array}$ & $\begin{array}{l}\text { Rachaduras, colapso } \\
\text { parcial de paredes não } \\
\text { estruturais. }\end{array}$ \\
\hline $3(40-60 \%)$ & $\begin{array}{l}\text { Deformações importantes. Rachaduras } \\
\text { abertas. Estruturas e estabilidade afetadas. } \\
\text { Evacuação necessária. }\end{array}$ & $\begin{array}{l}\text { Primeiro andar bastante } \\
\text { afetado, paredes e } \\
\text { colunas estruturais } \\
\text { danificadas. }\end{array}$ \\
\hline $5(70-80 \%)$ & $\begin{array}{l}\text { Colapso parcial do telhado e rachaduras nas } \\
\text { paredes. Médio potencial de causar morte. } \\
\text { Evacuação necessária. }\end{array}$ & $\begin{array}{l}\text { Padrão da casa ainda } \\
\text { identificável }\end{array}$ \\
\hline & $\begin{array}{l}\text { Colapso parcial a total. Alto potencial de } \\
\text { causar morte. Evacuação necessária. }\end{array}$ & $\begin{array}{l}\text { Destruição de mais de } \\
50 \% \text { da edificação. }\end{array}$ \\
\hline
\end{tabular}

também foi usada para avaliar as perdas de parcelas e material agrícola durante as inundações de agosto 2010 na Republica de Jibuti- costa nordeste da África (Vinet et al, 2012). Neste contexto o método foi adaptado para avaliar os danos da catástrofe do Megadesastre da região Serrana do Rio de Janeiro, aplicado ao caso do córrego do Príncipe (Tabela 1).

Os danos foram classificados através de trabalho de campo associado à análise de imagens aéreas e fotos logo após o desastre. Os danos de tipo 3, 4 e 5 foram considerados como de perda de infraestrutura.

Como não existiam arquivos vetoriais das construções existentes antes da catástrofe, foi efetuada uma vetorização a partir da análise das imagens de satélite Quickbird de agosto de 2006. Para comparação e identificação das moradias completamente destruídas pela catástrofe foi utilizada a imagem aérea de 2011. Esta manipulação integra algumas incertezas e considera-se que não houve modificações significativas de construção entre 2006 e 2011.

\section{Resultados}

Na bacia do Príncipe a corrida de detritos se estendeu por aproximadamente $4,8 \mathrm{~km}$, iniciando no bairro de Campo Grande, atravessando o bairro de Posse até o bairro Cascata do Imbuí no encontro do córrego
Príncipe com o rio Paquequer. Em termos comparativos apresentou menor extensão que as demais corridas de grande mortalidade na região Serrana (Vieira, Cuiabá e $\mathrm{D}^{\prime}$ Antas) que ocorreram simultaneamente (Rodrigues et al., 2012; Melo et al., 2011; Pinto \& Freitas, 2013).

As observações de campo e identificação de processos permitiram a delimitação e a descrição de duas zonas: a zona de erosão/transporte e a zona de deposição além de 4 pontos de estrangulamento. Estes últimos são definidos como níveis de base temporários e locais (Silva \& Santos, 2010) onde a configuração geomorfológica de estreitamento do vale resulta num barramento natural do curso de água favorecendo a criação de barragens num período de chuvas intensas. Quando ocorre a ruptura da barragem o fluxo liberado é mais viscoso e de maior capacidade destrutiva. Pontos de estrangulamento também foram igualmente identificados nas corridas de detritos dos vales de Cuiabá, Vieira e D’Antas durante o mesmo evento catastrófico (Melo et al., 2011; Fraifeld \& Freitas, 2013; Pinto \& Freitas, 2012).

As características destas zonas estão na tabela 2 e podem ser visualizadas na Figura 2. A zona de transporte se estendeu por uma distância de $2,06 \mathrm{~km}$ cobrindo uma área de 20 ha (aproximadamente $2 \%$ da área da bacia do córrego do Príncipe), enquanto a zona de deposição se prolongou por 2,73 $\mathrm{km}$ atingindo 28,4 ha (aproximadamente $2,5 \%$ da área da bacia do córrego do Príncipe). 
Tabela 2: Características de cada zona nas cotas topográficas.

\begin{tabular}{|c|c|c|c|c|c|}
\hline Zona & $\operatorname{Cota}(\mathrm{m})$ & Material & Fonte & Geomorf. & Processos \\
\hline & $\begin{array}{l}\text { Acima de } \\
1000\end{array}$ & Argila a blocos & $\begin{array}{l}\text { Colúvio } \\
\text { Encostas }\end{array}$ & Vale estreito & Deslizamentos planos superficiais \\
\hline \multirow{6}{*}{ 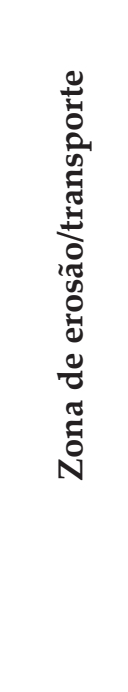 } & 1350 & $\begin{array}{l}\text { Megablocos } \\
\left(\geq 10 \mathrm{~m}^{3}\right)\end{array}$ & Encostas & Vale estreito & $\begin{array}{l}\text { Corrida de detritos secundária } \\
\text { desconectada da principal }\end{array}$ \\
\hline & 1000 & $\begin{array}{l}\text { Argila a blocos } \\
\left(\leq 10 \mathrm{~m}^{3}\right)\end{array}$ & $\begin{array}{l}\text { Depósitos } \\
\text { antigos }\end{array}$ & Estrang. 1 & $\begin{array}{l}\text { Formação de barragem e ruptura desta. } \\
\text { Exumação e transporte de blocos }\end{array}$ \\
\hline & $\begin{array}{l}1000 \text { até } 1^{\text {as }} \\
\text { casas }\end{array}$ & $\begin{array}{l}\text { Argila a blocos }(\leq \\
\left.3 \mathrm{~m}^{3}\right)\end{array}$ & $\begin{array}{l}\text { Encostas e } \\
\text { leito do rio }\end{array}$ & Vale estreito & $\begin{array}{l}\text { Deslizamentos planos e superficiais. } \\
\text { Erosão do leito, exposição e transporte } \\
\text { de blocos de depósitos antigos }\end{array}$ \\
\hline & 980 & Argila a blocos & Encostas & Vale largo & $\begin{array}{l}\text { Corridas secundarias conectadas a } \\
\text { corrida principal }\end{array}$ \\
\hline & 970 & Argila a blocos & $\begin{array}{l}\text { Depósitos } \\
\text { antigos e leito } \\
\text { do rio }\end{array}$ & Vale largo & $\begin{array}{l}\text { Escavação do leito maior, transporte e } \\
\text { deposição de blocos }\end{array}$ \\
\hline & 910 & Argila a blocos & $\begin{array}{l}\text { Depósitos } \\
\text { antigos e leito } \\
\text { do rio }\end{array}$ & Estrang. 2 & $\begin{array}{l}\text { Formação de barragem inundação a } \\
\text { montante e rutura da barragem }\end{array}$ \\
\hline \multirow{2}{*}{ 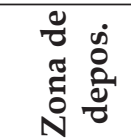 } & 870 & \multirow{2}{*}{$\begin{array}{l}\text { Predomínio de } \\
\text { material fino }\end{array}$} & \multirow{2}{*}{ Encostas e canal } & Estrang. 3 & \multirow{2}{*}{ Deposição } \\
\hline & 860 & & & Estrang. 4 & \\
\hline
\end{tabular}

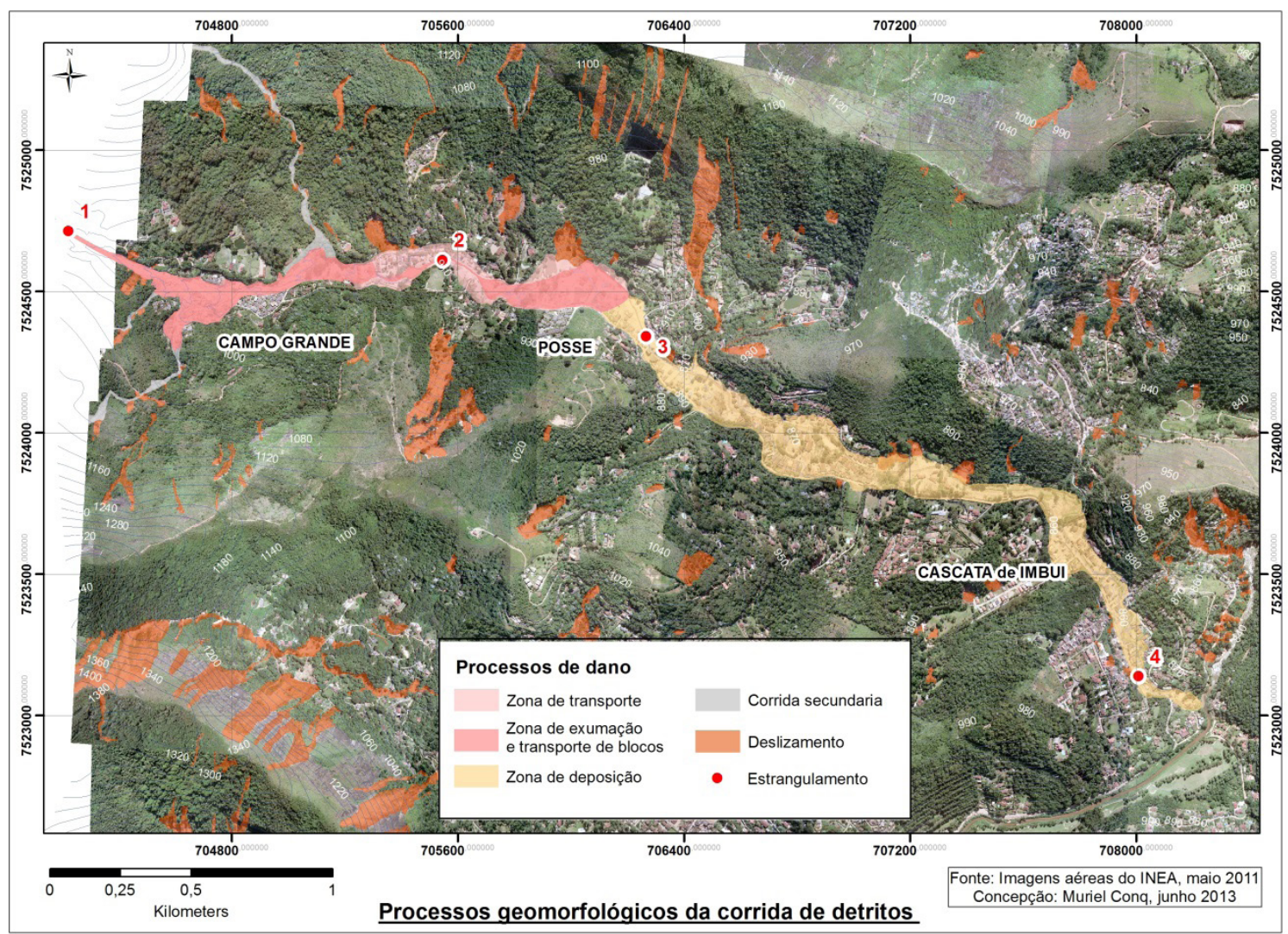

Figura 2: Mapa com delimitação da extensão e zonas da corrida de detritos com os diferentes processos geomorfológicos 
$3 \mathrm{~A}$

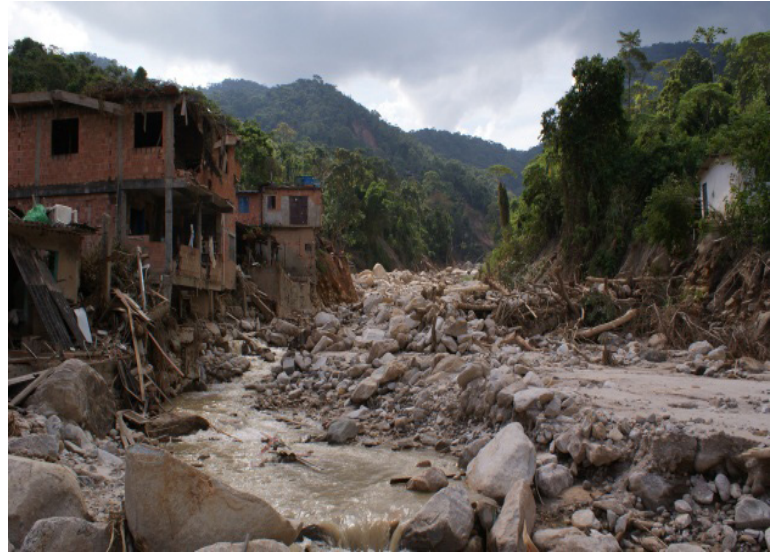

$3 \mathrm{~B}$

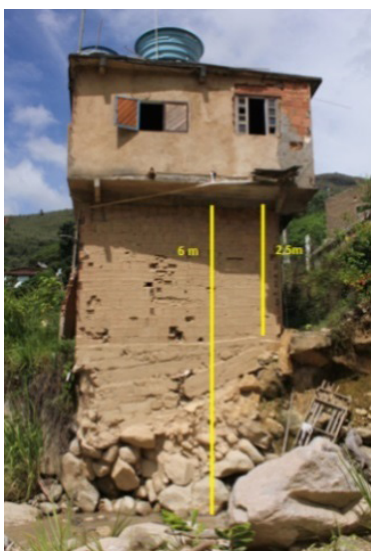

Figura 3: a) Erosão do leito maior em Campo Grande, destacando-se a grande quantidade de blocos. b) Casa danificada. A escavação do leito do rio tem em torno de 3,5 $\mathrm{m}$ (vide na figura $\mathrm{b}$ as escalas de $6 \mathrm{~m}$ e 2,5 m)

\subsection{Zona de erosão e transporte}

A zona de transporte representa a área onde o processo dominante foi a erosão e o transporte de material de diferente granulometria. Esta se estende da cota 1000 até a cota 870 . Ao longo do eixo do rio no bairro de Campo Grande uma grande quantidade de blocos e matacões com dezenas de metros cúbicos cobriram o leito do rio (Figura 3a). Os materiais finos foram erodidos e transportados no fluxo do rio, o que resultou numa escavação vertical do leito do rio deixando expostos depósitos sedimentares mais antigos. Processo similar também foi observado para o vale do córrego D'Antas em Friburgo (Pinto e Freitas, 2012)

A jusante da cota 1000 foram observados escorregamentos superficiais e translacionais nas encostas. Estes movimentos de massa transportaram um material fino deixando expostos, ao pé da encosta, blocos e matacões. Não foi observada nenhuma marca de erosão ou outro indicio que indicasse alimentação de blocos pelas encostas e vales laterais. Essas observações sugerem que os blocos foram majoritariamente originados pela exumação de depósitos antigos presente no leito do rio a jusante da cota 1000. A partir da cota $920 \mathrm{~m}$ na zona de transporte a corrida de detritos apresentou também muitos troncos de arvores e escombros de casas.

Uma das evidências deste processo de erosão com exumação dos blocos é retratada na Figura $3 b$ onde foi constatada a escavação do fundo do leito estimado a 3,5 m. No vale do Vieira, Fraifeld e Freitas (2013) estimaram em $6 \mathrm{~m}$ a incisão vertical. Esta erosão colocou em evidencia a presença de um deposito antigo composto de blocos, descrito por Waldherr et al (2011) e sobre o qual várias casas foram construídas.

Ao longo da área onde houve erosão e transporte de blocos foi observada a diminuição do tamanho das partículas: desde matacões com mais de $10 \mathrm{~m}^{3}$ a montante, até blocos de $2 \mathrm{~m}^{3}$ na cota 873 , ponto de observação que permitiu marcar o limite entre as zonas de erosão/ transporte e de deposição com grande quantidade de material de granulometria mais fina que areia a jusante.

De acordo com observações de campo os processos que afetaram a área classificada como zona de erosão/ transporte incluem: deslizamentos de encostas, corridas de detritos desconectadas com a corrida principal, a erosão do fundo do leito com a exumação dos blocos e matacões. Estima-se que eles tenham sido transportados até uma distância de $2 \mathrm{~km}$.

\subsection{Pontos de estrangulamento}

Na corrida de detritos do córrego do Príncipe foram observados quatro pontos de estrangulamento, onde o vale se estreita consideravelmente e que ocasionaram a formação de barragens naturais. A montante destes pontos as alturas de lama observadas (entre $3 \mathrm{~m}$ e $6 \mathrm{~m}$ ) foram maiores que em outros pontos do vale (entre 1 $\mathrm{m}$ e $2 \mathrm{~m}$ ).

O ponto de estrangulamento mais a montante, localizado na cota $1000 \mathrm{~m}$, foi associado a um deposito de um antigo escorregamento (Waldherr et al, 2011). O segundo ponto de estrangulamento está localizado sobre o eixo principal da drenagem, na cota $910 \mathrm{~m}$, próximo às primeiras casas do bairro da Posse. A largura do leito principal era de aproximadamente $20 \mathrm{~m}$ e as moradias nas margens não sofreram danos colaterais. Esta observação permite se supor que que os blocos encontrados a jusante não passaram por este estrangulamento. Alguns metros a montante deste estrangulamento as marcas da lama ainda visíveis nos muros das casas e na folhagem indicam uma altura de lama máxima de $3 \mathrm{~m}$.

O terceiro ponto de estrangulamento, na cota 870 $\mathrm{m}$, está representado nas Figuras 4a e 4b. O nível do rio atingiu $6 \mathrm{~m}$ acima do seu leito (marca da lama). De acordo com fotos e relatos de moradores a largura do leito menor uma semana depois do desastre era de aproximadamente 10 metros muito acima dos $3 \mathrm{~m}$ que normalmente ele apresenta. 
$4 \mathrm{~A}$

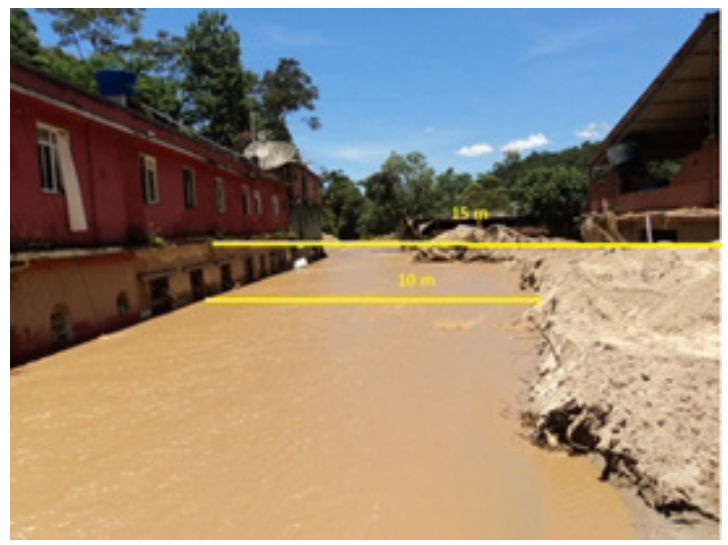

$4 \mathrm{~B}$

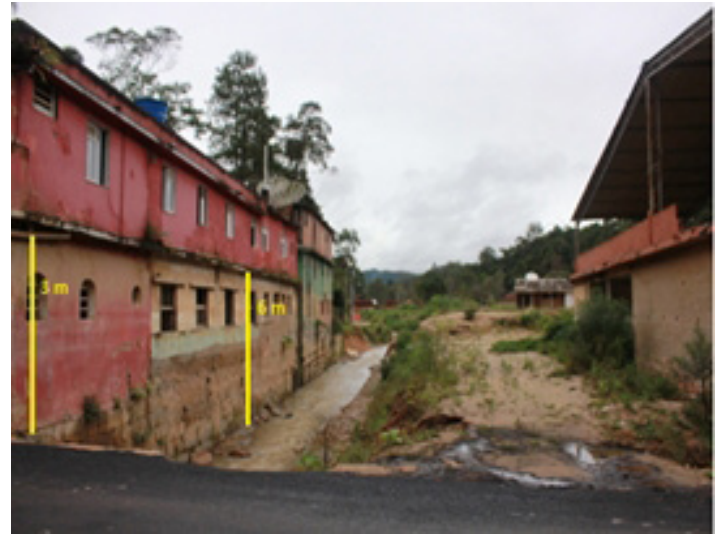

Figura 4: a) Inundação no terceiro ponto de estrangulamento no eixo principal de drenagem oito dias depois do evento; b) mesmo local em maio 2012.

A jusante do vale, próximo à escola pública da localidade Cascata de Imbui, localiza-se o quarto ponto de estrangulamento. A partir de observações de campo foi constatado que a altura de lama atingiu $4 \mathrm{~m}$ acima do nível normal do rio.

\subsection{Zona de Deposição}

Na zona de deposição o processo dominante foi a sedimentação de material fino (areia a argila) que em alguns locais superou os $2 \mathrm{~m}$ de espessura afetando parte das moradias e vias. A inundação afetou todo o vale do Príncipe e o rio ficou com sua cota acima do normal durante varias semanas. Especialmente a montante do ponto de estrangulamento 3 (Figuras $4 \mathrm{a}$ e $4 \mathrm{~b}$ ) sedimentação mínima foi de $0,9 \mathrm{~m}$ e a marca da lama atingiu os $3 \mathrm{~m}$ a partir do nível da rua.

A zona de deposição apesar de extensa $(2,73 \mathrm{~km}$, ou mais de 50 \% da extensão do fluxo) não se conectou com o canal da drenagem principal da região (rio Paquequer). May \& Gresswell (2004) classificam estes fluxos de detritos como do tipo depósitos suspensos e confinados a vales tributários. Eles são típicos de vales tributários que apresentam maior distância até a confluência com o canal principal e largos, retendo temporariamente este material. Depósitos formados nestas áreas podem ser escavados por fluxos de detritos posteriores ou formarem uma superfície de agradação que retem estes mesmos.

\subsection{Material fonte para alimentar a corrida de detritos}

Com base em observações de campo foi constatado no alto curso do vale do córrego do Príncipe o embricamento de blocos de dezenas de metros de diâmetro indicando que devem ter sido remobilizados pelo fluxo. A fonte deles foi à exumação de depósitos antigos, que também contribuíram com material mais fino. A erosão das encostas através dos deslizamentos laterais também foi uma importante fonte de material.

Assim sugere-se que na noite de 11 de janeiro 2011 as chuvas torrenciais provocaram o aumento do nível do córrego rapidamente, transportando inicialmente material fino. Com o enriquecimento de material fino o fluxo aumentou a sua viscosidade permitindo a erosão do fundo do vale (Figura 5) e das encostas no contato direito com o córrego. Assim foram exumados os blocos que foram remobilizados.

O primeiro indício de transporte de blocos foi mapeado na cota 1000 considerado como o primeiro ponto de estrangulamento. $\mathrm{O}$ aumento do poder de transporte do fluxo favoreceu a escavação do leito do rio e a exumação de mais matacões e blocos (Figura 5). Na sua progressão, o fluxo erodiu a base das encostas, desestabilizando-as e provocando mais escorregamentos, o que aconteceu a jusante, ao longo do vale nas cotas 980,915 e $890 \mathrm{~m}$.

Nos sistemas de drenagem afluentes ao córrego foram

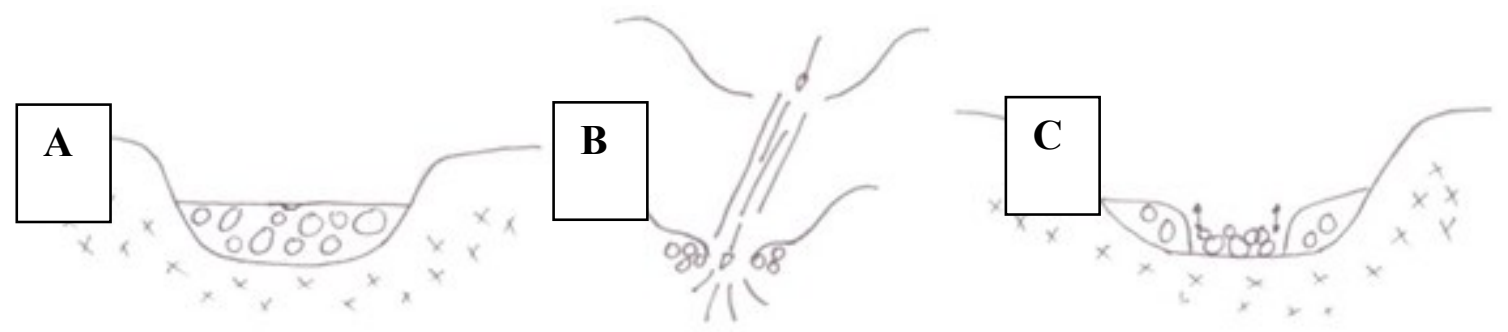

Figura 5: Esquema no canal principal do processo de exumação de blocos de depósitos antigos. 
observados os mesmos processos observados no vale a montante da cota 1000, contribuindo também como uma fonte de alimentação, principalmente de material fino e de maneira mais limitada em material grosso e blocos. Eles foram definidos e mapeados como corridas secundarias. Os blocos encontrados no eixo do fluxo destas corridas secundárias participaram principalmente na amplificação da destruição das laterais do vale em Campo Grande. Efetivamente não foram observadas marcas de erosão que indicariam um transporte de grande quantidade de blocos. Ou seja, também não foram fonte direta dos blocos transportados na corrida principal.

\subsection{Os danos}

A Figura 6 apresenta o mapa da área com a classificação de intensidade de danos. Observa-se que o bairro Campo Grande é o que teve danos de maiores intensidades. Entretanto, uma grande área com intensidade de dano baixa (1) pode ser explicada por estar situada a jusante do ponto de estrangulamento 2 .

Nesta localidade grande parte das casas situadas nas margens dos leitos menor e maior (mesmo distantes mais de $50 \mathrm{~m}$ do canal) foi muito destruída. Neste caso a altura foi decisiva para limitar o numero de edificações perdidas

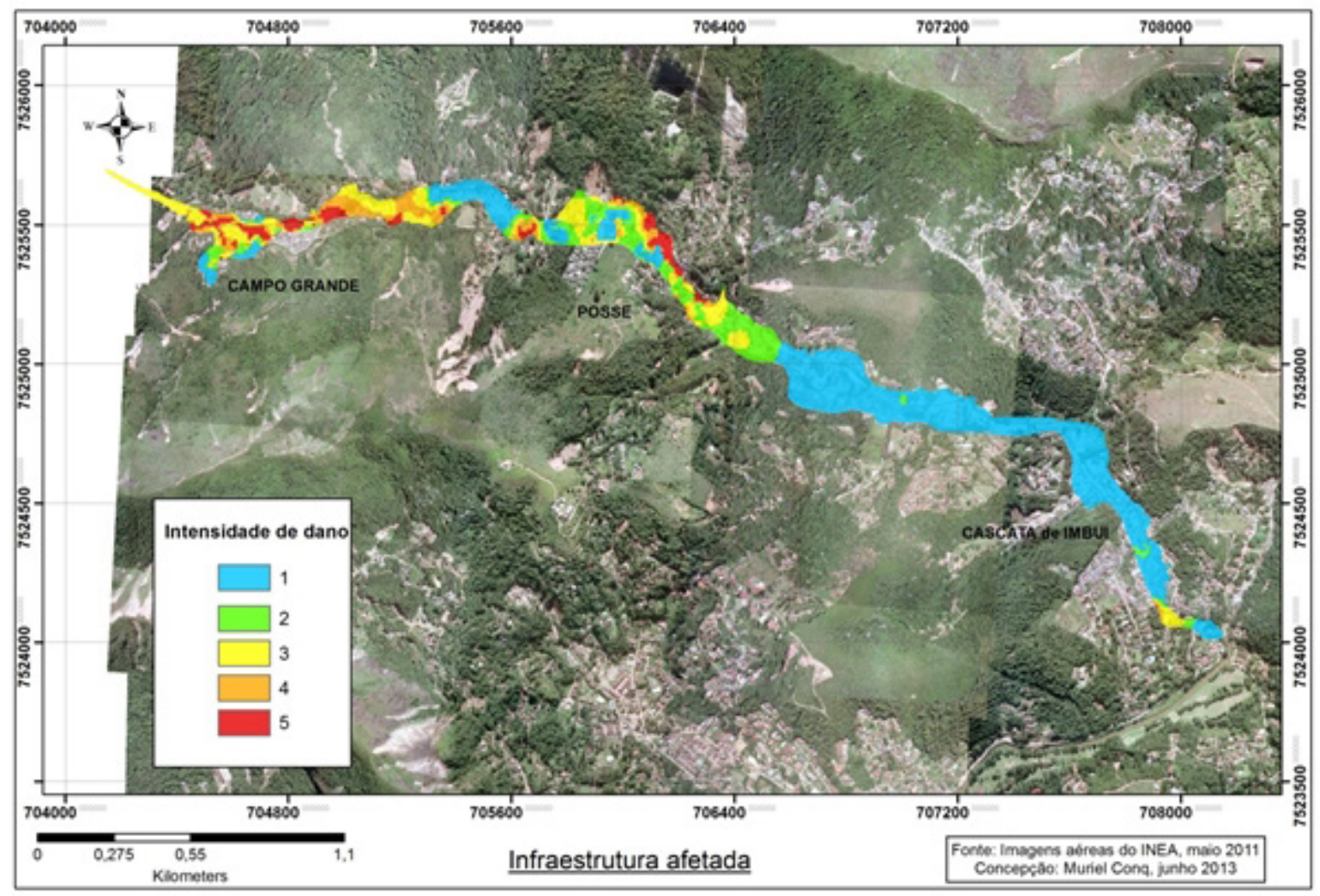

Figura 6: Mapa com intensidade de dano de infraestrutura.

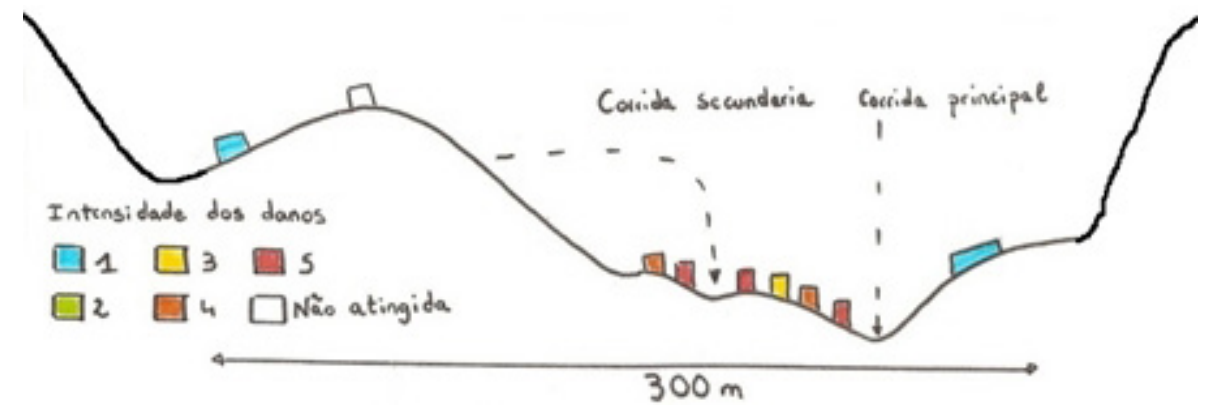

Figura 7: Vista em corte esquemática perpendicular à direção do fluxo da distribuição dos danos no bairro de Campo Grande. 
$8 \mathrm{~A}$

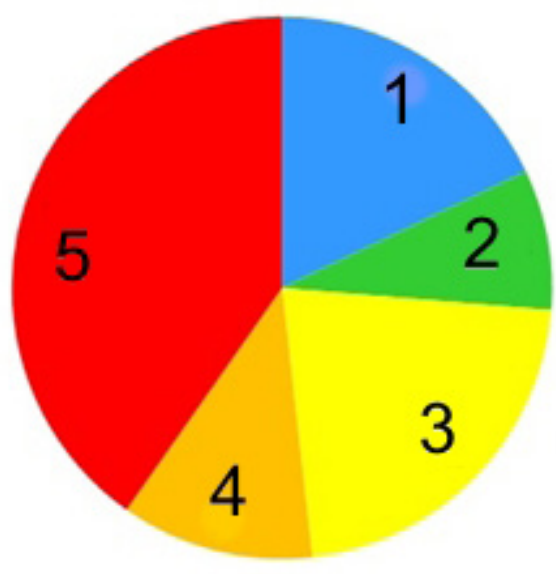

8B

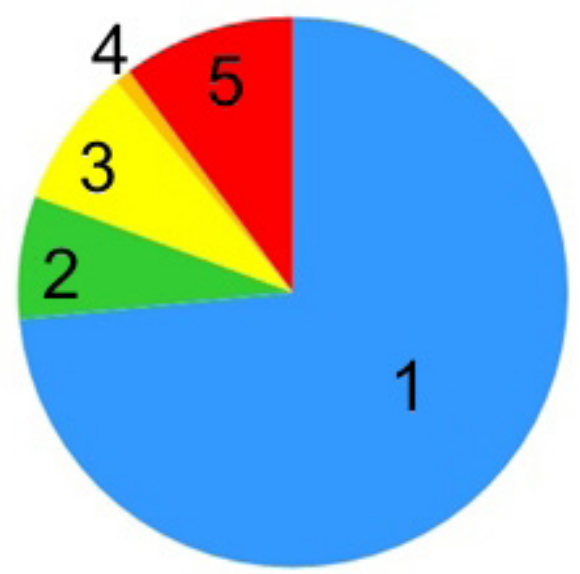

Figura 8: Distribuição em porcentagem das construções afetadas por danos de diferentes intensidades (1 a 5) na bacia do córrego do Príncipe. A: Zona de transporte e B: Zona de deposição.

(Figura 7). De forma similar, a jusante, na localidade de Posse, as casas que se encontravam a menos de $80 \mathrm{~m}$ da drenagem sofreram danos de intensidade entre 3 e 5. Entretanto, a mais afastadas (além de $80 \mathrm{~m}$ do eixo do canal) sofreram somente dano de intensidade 1.

Na zona de deposição os maiores danos se concentraram na região a montante dos pontos de estrangulamento.

As casas próximas aos pontos de estrangulamento (principalmente os pontos 2 e 3 ) foram destruídas pelos escombros transportados e pela sedimentação da corrida e submergidas pelo lago que se formou. Esse fenômeno também foi observado em menor escala no ponto de estrangulamento 4 (bairro Cascata do Imbuí). Em termos de intensidade de danos o bairro Cascata de Imbuí sofreu menos por conta dos sucessivos pontos de estrangulamento a montante que aturaram como barragem temporária a corrida principal.

Com base no mapeamento de campo e a análise dos mapas constatou-se que a área total de edificações afetadas foi de $65.585 \mathrm{~m}^{2}$, sendo $27.213 \mathrm{~m}^{2}$ (42\%) na zona de transporte e $38.372 \mathrm{~m}^{2}$ (58 \%) na zona de deposição. No total 5,6 km de vias foram afetadas, sendo $1,9 \mathrm{~km}$ na zona de transporte e $3,7 \mathrm{~km}$ na zona de deposição. Apesar de na zona de transporte a área de edificações afetadas ter sido menor, os danos foram de maior intensidade. Os danos de intensidades 4 e 5 ocorreram principalmente na zona de transporte $(85 \%$ das moradias com estes níveis de danos estão na zona de transporte.

De acordo com a Figura 8 na zona de transporte perto de $54 \%$ das casas foram completamente ou em parte destruídas (intensidades 4 e 5) sendo a reconstrução muito difícil. A zona de deposição apresenta maior quantidade de área afetada, no entanto os danos foram de menor intensidade .

Os resultados mostraram que na zona de transporte o nível de perda de infraestrutura (intensidade de dano 3,4 e 5 ) das moradias atingiu $61 \%$ contra $20 \%$ na zona de deposição (Figura 8). O nível de perdas no vale inteiro atingiu assim o valor médio de $42 \%$.

\section{Conclusão}

As chuvas torrenciais que ocorreram em janeiro de 2011 na região Serrana do Rio de Janeiro desencadearam no córrego do Príncipe umas das corridas de detritos mais destruidoras do município de Teresópolis. A área da corrida de detritos atingiu aproximadamente $5 \%$ da bacia do córrego do Príncipe, mas provocou danos de grande intensidade. A corrida de detritos se estendeu por aproximadamente $4,8 \mathrm{Km}$, sendo os dois primeiros caracterizados por processos de erosão e transporte de blocos, matacões e material fino. Os últimos 2,8 km foram de deposição deste material. Quatro pontos de estrangulamento, mapeados ao longo desta corrida, favoreceram a acumulação de lama a montante e tiveram importância na definição espacial dos danos. O fluxo de detritos gerou um depósitos suspenso, confinado ao vale do Príncipe, não alcançando a drenagem principal (rio Paquequer). Segundo May \& Gresswell (2004) este processo geralmente ocorre em vales tributários largos e cujas confluências com o canal principal sejam distantes.

A área classificada como zona de erosão/transporte foi caracterizada por deslizamentos de encostas, corridas de detritos desconectadas com a corrida principal e erosão do fundo do leito. Os blocos e matacões foram originados principalmente pela exumação de depósitos antigos do leito do rio, foram transportados até $2 \mathrm{~km}$ de distância e mostraram uma diminuição gradativa de tamanho a jusante. Na zona de deposição o processo dominante foi a sedimentação de material fino (areia a argila) que em alguns locais superou os $2 \mathrm{~m}$ de espessura soterrando parte das moradias e vias.

As chuvas torrenciais provocaram o aumento do nível do córrego rapidamente, transportando inicialmente material fino e aumentando a viscosidade do fluxo. $\mathrm{O}$ 
aumento do poder de transporte do fluxo favoreceu a escavação do leito do rio e a exumação de matacões e blocos. Na sua progressão, o fluxo erodiu a base das encostas, desestabilizando-as e provocando mais escorregamentos.

Os danos observados foram relacionados com a vulnerabilidade estrutural das construções e associados com os fatores geomorfológicos da corrida de detritos permitindo a elaboração de cenários de catástrofe, e um melhor gerenciamento do risco. Os danos de intensidades 4 e 5 ocorreram principalmente na zona de transporte (85\% das moradias com estes níveis de danos estão na zona de transporte). Nestes casos os fatores decisivos para evitar danos de infraestrutura nas edificações foram principalmente a maior diferença de altitude com relação ao canal principal e secundariamente a maior distância deste. Na zona de transporte/erosão mais de $50 \%$ das construções foram completamente ou em parte destruídas (intensidades 4 e 5). Na zona de deposição os maiores danos se concentraram na região a montante dos pontos de estrangulamento. As casas próximas aos pontos de estrangulamento foram destruídas pelos escombros transportados e pela sedimentação da corrida e submergidas pelo lago que se formou. Em termos de intensidade de danos o bairro mais a jusante (Cascata de Imbuí) sofreu menos por conta dos sucessivos pontos de estrangulamento a montante que atuaram como barragem temporária a corrida principal, também por estar situado mais longe da fonte da corrida. Apesar da zona de deposição apresentar uma área afetada maior, os danos foram de menor intensidade. O nível médio de perdas de construções (de difícil reconstrução) no vale do córrego do Príncipe foi de $42 \%$.

A observação de remobilização de blocos e depósitos antigos é uma evidência que a região já foi assolada por outros eventos de corridas de detritos. Por isso sugerese que a liberação de áreas para construção na região Serrana do Rio de Janeiro seja precedida de estudos de risco detalhados para prevenir novas catástrofes associadas à urbanização em vales íngremes e encaixados.

\section{Referências}

AMARAL, C.; LIMA, F.I.; VAREJÃO, L.C.; SANTANA, $\mathrm{M}$. Carta de risco remanescente a escorregamentos no município de Teresópolis, após o megadesastre' 11 da Região Serrana. In: CONGRESSO BRASILEIRO DE GEOLOGIA DE ENGENHARIA E AMBIENTAL, 13, 2011, São Paulo. Anais... São Paulo: ABGE, 2011, CD-ROM

AMARAL, C.; VARGAS, E.; KRAUTER, E.; Analysis of Rio de Janeiro Landslide Inventory Data. In: INTERNATIONAL SYMPOSIUM ON LANDSLIDES, 17, 1996. Rotterdam, Proc... Rotterdam : Balkema. 1996. p. 1843-1846.
AVELAR, A. S.; COELHO NETTO, A. L.; LACERDA, L. W. A.; BECKER, B. AND MENDONÇA, M. B. Mechanisms of the recent catastrophic landslides in the mountainous range of Rio de Janeiro, Brazil. In: WORLD LANDSLIDE FORUM, 2, 2011, Roma. Anais... Roma: IPL, 2011, CD-ROM

DOURADO, F.; COUTINHO, T.; FERNANDES, M. O Megadesastre da Região Serrana do Rio de Janeiro - as Causas do Evento, os Mecanismos dos Movimentos de Massa e a Distribuição Espacial dos Investimentos de Reconstrução no Pós-Desastre. Anuário do Instituto de Geociências, Rio de Janeiro, v. 35, n 2, p. 43-54, 2012.

DRM-RJ. Serviço Geológico do Estado do Rio de Janeiro. Diagnóstico do Megadesastre da Região Serrana, janeiro de 2011. Rio de Janeiro: DRM, 2011

FELL, R.; COROMINAS, J.; BONNARD, C.; CASCINI, L.; LEROI, E.; SAVAGE, W.Z. Guidelines for landslide susceptibility, hazard and risk zoning for land use planning. Engineering Geology, v. 102, p. 85-98, 2008

FERNANDES, N.F.; GUIMARÃES, R.F.; GOMES, R.A.T.; VIEIRA, B.C.; MONTGOMERY, D.R.; GREENBERG, H. Topographic controls of landslides in Rio de Janeiro: field evidence and modeling. Catena, V. 55, p. 163181, 2004.

FRAIFELD, F.; FREITAS, M.M. Considerações geomorfológicas a respeito da corrida de massa do rio Vieira, Teresópolis - RJ. GeoPUC - Revista do Departamento de Geografia da PUC - Rio, Rio de Janeiro, v. 5, n. 10, p. 1-16, 2013.

GONZALEZ, M. Aplicação dos métodos Fuzzy e Bayesiano para o estudo de instabilidades de encostas no município de Teresópolis, RJ, 2000. 156 f., Dissertação (Mestrado), Universidade Federal do Rio de Janeiro, Rio de Janeiro, 2000.

HARTWIG, M.E. Tectônica rúptil Mesozoico-Cenozoica na região da Serra dos Órgãos, RJ. 2006. 134 f., Dissertação (Mestrado), Universidade de São Paulo - Instituto de Geociências, São Paulo, 2006.

IBGE. Instituto Brasileiro de Geografia e Estatística. Censo 2010. Disponível em: http://www.ibge.gov.br/ censo2010/, acessado em Jun. 2013.

KANJI, M.A.; MASSAD, F.; CRUZ P.T. Debris flows in areas of residual soils: occurrence and characteristics In: INTERNATIONAL WORKSHOP ON OCCURRENCE AND MECHANISMS OF FLOWS IN NATURAL SLOPES AND EARTHFILLS (IW-FLOWS), 2, 2003, Sorrento. Proc... Sorrento: Associazione Geotecnica Italiana, 2003. p. 1-11 
LACERDA, W. Landslide initiation in saprolite and colluvium in Southern Brazil: Field and laboratory observations. Geomorphology, v. 87, p. 104-119, 2007

LEONE, F.; ASTE, J-P.; LEROI, E. L'évaluation de la vulnérabilité aux mouvements de terrains : pour une meilleure quantification du risque/ The evaluation of vulnerability to mass movements : towards a better quantification of landslide risks. Revue de géographie alpine, v. 84 n. 1, p.35-46, 1996.

LEONE, F.; VINET, F.; DENAIN, J-C.; BACHRI, S. Developing a spatial analysis methodology of the destruction caused by the tsunami of 26 December 2004 (Banda Aceh). First results for the production of future risk scenarios, Géocarrefour, v. 82 n. 1-2, p.77-90, 2007.

MAY, C.L.; GRESSWELL, R.E Spatial and temporal patterns of debris-flow deposition in the Oregon Coast Range, USA. Geomorphology, v. 57 p. 135-149, 2004

MELO, R.; VAREJÃO, L.C.; DOURADO, F. Megadesastre'11 da Serra Fluminense: a corrida de massa do vale do Cuiabá, em Itaipava/Petrópolis, Análise preliminar dos condicionantes geológicos. In: CONGRESSO BRASILEIRO DE GEOLOGIA DE ENGENHARIA E AMBIENTAL, 13, 2011, São Paulo. Anais... São Paulo: ABGE, 2011, CD-ROM

PINTO, R.W.P.; FREITAS, M.M. Considerações a respeito dos movimentos de massa ocorridos em janeiro de 2011 na bacia do córrego D’ Antas, Nova Friburgo. RJ GeoPUC - Revista do Departamento de Geografia da PUC - Rio, Rio de Janeiro, v. 5, n. 9, p. 79-96, 2012.

RODRIGUES, J.; TUPINAMBÁ, M.; AMARAL, C. A corrida de massa do rio Vieira em Teresópolis, sudeste do Brasil: caracterização da área fonte dos sedimentos transportados. Anuário do Instituto de Geociências - UFRJ, Rio de Janeiro, v. 35, n. 2, p. 152-164, 2012.

SILVA, T.M. \& SANTOS, B.P. Sistemas de drenagem e evolução da paisagem Revista Geografica Acadêmica v.4, n.1 p. 5-19, 2010.

SILVEIRA C. S., SOUZA K. V. Relações hidrológicas entre a pluviosidade e a vazão em uma série temporal (2007-2009) de uma bacia de drenagem de uso misto. Geociências, São Paulo, v.31, n.3, p. 395-410, 2012. Disponivel em: http://ppegeo.igc.usp.br/pdf/geosp/ v31n3/v31n3a07.pdf.

SMYTH, C.G.; ROYLE, S.A. Urban landslide hazards: incidence and causative factors in Niteroi, Rio de Janeiro State, Brazil. Applied Geography, v. 20, p. 95-117, 2000.
UERJ/IBGE - Universidade do estado do Rio de Janeiro/ Instituto Brasileiro de Geografia Estatística Estudo ambiental como subsídio ao orçamento territorial através de análise de caso: Município de Teresópolis - (Relatório Final). Projeto PADCT, 3 volumes, 1999.

VINET F. (coord), Mission d'expertise - Rapport sur les crues de l'Oued Gobaad à As Eyla (République de Djibouti, Août 2010), Processus, Impacts et Rémediation - Univesité de Montpellier III - GRED, 124 p., 2012.

WALDHERR R.F. Zonas de estrangulamento durante corrida de detritos no córrego do Príncipe, TeresópolisRJ, 29f. Monografia, Pontifícia Universidade Católica do Rio de Janeiro, Rio de Janeiro, 2011. 